\title{
An Empirical Study of Educational Inequalities in Rural and Urban Areas of Pakistan
}

\author{
Ayjaz, Ahmed*, Hira Mujabid**
}

\begin{abstract}
The central object of this paper is to give detailed analysis of educational disparity in Pakistan. This study is examined all over provinces of rural and urban of Pakistan including Islamabad for the period of 2014-15 and the data is used from PSLM. In particular, we calculate education inequality all over the population and beyond the employed population. This study is investigated individually male and female having age equal to 15 years and over and are not being enrolled in any educational institutions. The study finds that there is lack of education over the populace. Whereas, strength of education disparity is extremely low athwart in employed people. When we compare rural-urban areas of Pakistan. The study find that urban areas are less disparity in education as compare to rustic areas. The study also investigates that education inequality are extra serious amid female than male. The province wise contrast shows that education inequality is high in Baluchistan and Sindh while there is less education disparity is Islamabad.
\end{abstract}

Keywords: Earnings, education, inequality, population.

JEL Classification: I00, I2, I24

\section{INTRODUCTION}

According to the Education for All (EFA) Development Index (EDI), Pakistan is placed 118 out of 129 countries. Education is a significant role in economic expansion of the state. It takes complete estimate to get rid of discrimination on the basis of gender and to device strategies for equal education to all. Unfortunately, Pakistan is placed in education as lowest among the South Asian countries. Secondly, Pakistanis completely failed to meet the MDGs. It is necessary to meet the MDGs and need to alter their attitudes, values, and practices in education. The Centre object is to measure educational inequality at different provinces of Pakistan in rural and urban areas specially; these studies will give the measurement of gender inequality that occurs in education at provinces of Pakistan. Education is the main tool to compute the growth of a country. Pedagogy does not only develop the human capital of the group but also add a civilized society as well. They work only the prosperity of the group in the absence of any dangerous condition. It is basic right of every people to get equal education to all level of education. It can be noticed from the previous literature that educational gaps exist among various groups within country. Human capital takes part in the economic development of the state. Witzke (1984) indicates that land and physical capital do not play an important role but moral capital and more human benefits are the solution of economic progress. Schultz (1961) has given value of outlay in human capital. Human capital is the most important factors in case of various studies indicated a pivotal role in economic growth.

\footnotetext{
*Assistant professor/Senior Subject Specialist, School Education Department, Government of Sindh, Karachi, Pakistan.Email: aijazahmed425@yahoo.com

**Assistant professor, College of Economic and Social Development, Institute of Business Management, Karachi, Pakistan.Email: hira.mujabid@iobm.edu.pk (Corresponding Author)
} 
It is proverbial that pedagogy is an indispensable component of mortal capital. Investment can be sustainable in human capital through education only. Education makes up human capital more productive in every field of life. They can work efficiently and more productive. The various studies show a favorable effect in education and earning (Turcinkova \& stavkova, 2012). The situation is same in Pakistan as well. The table 1 indicates that large pedagogy masses earn more than uneducated people. The computation is formed (PSLM) from 2015 to 2016.

In addition, the Table 1 that means earning raises measure education. Examples the average obtaining money of graduates is 3.5 times greater than illiterate earners. It evidently seems to be rational difference, when we incorporate the cost of education, cost of time, opportunity cost and monetary cost are measured then there is no much high difference between average earnings of illiterate and graduates. It could be possible for non-educational factors have a positive number of illiterates are medium and small level of farmers. In same way, some farmers started their own business through legacy. Therefore, each of such type people is higher than graduates' masses. The levels of primary (5-9) of the earning people are about half more than illiterate masses. It indicates that on average, every coming level of schooling is more productive. Pedagogy is foundation effect in earning and distinction and cause of different earning. According to small data of PSLM (2015-16) indicates so inequalities in Gini coefficient of obtaining of money is 0.474 in Pakistan that show very big. According to table 1, Educational difference attainments are a key source of earning.

Table 1. Education and Average Earnings in Pakistan

\section{Years of Education Average Monthly Obtaining money in PKR}

\begin{tabular}{cc}
\hline $0-4$ & 9,957 \\
$5-9$ & 13,474 \\
$10-13$ & 18,708 \\
$14-15$ & 27,178 \\
16 and above & 34,582 \\
\hline
\end{tabular}

Source: Self-measurement of PSLM (2015-16)

\section{LITERATURE REVIEW}

This section provides the literature review of educational inequality. Pathania (2020) has tried to go through education inequality, literacy inequality and the progress of India. Male and female of literacy inequality re investigated from 1951 to 2011 through census wise data. It is evaluated at the national level. It is also examined at different level. It is also examined at different states of India and keeping in rural and urban education inequality is calculated at different level such as primary, elementary, higher secondary and higher education from 2005 to 2014. The results indicate that literacy inequality has decreased at different states of India but in case of rural areas, literacy inequality is still higher among females. The results are also stipulated that education inequality is higher in higher education level whereas primary, upper primary and higher secondary levels are low as compare to higher education levels. Yixuan (2020) is specified unprecedented migration and set up of Hukou system in China when migrant children have to face the minimum of education inequality when they enter into a new district. This type of problem has been based in China since 1980s. With the passage of time, the new policies have been started to help migrant children are increasing day by day. It is thoroughly paid attention to concentrate on the cognitive skills of middle school students in China. 
In empirical approach, the micro data is used and found that migrant students' performance is worst as compare to local students. Educational gaps occur between districts and provinces in China. The methodology is used OLS estimation and parameters are set for migrants' status dummies and districts dummies which are actually significant. It is verified that the ratio of local schools is provided school quality and the gaps create on the basis of cognitive skills in two dimensions. The results show that migrant children have no benefits in endowments as well as face enrollment difficulties owing to their migrant status. In fact, it is extremely disparity exists in public schools. The policy recommendation is to care the migrant teenagers and focus to provide the equality in education.

Abdelbaki (2012) explores the educational inequalities and income inequality that need to apprehend the commits and politicians in the fields of the national economy. There are some finding of the research that there is positive relation between family income and head of the family's education level. Secondly, the main cause of the educational inequality is the large gap of income inequality between income classes educational achievement has been decreased from 1980-2006. The results found that Education costs are the main disparities in education inequality in Bahrain due to existing of privates' schools in different governorates. The paper suggests that it is necessary to take notice by policy-makers to distribute private schools among governorates and is required to minimize the education cost in schools for improving income and educational inequality conditions in Bahrain.

Br. And Issue. (2011) examines the present state of knowledge on the effect of education inequality and income inequality on economic growth along with systematic and descriptive literature review. It presents theories statements and assumptions in context of the relationship between income and education inequality on economic growth. Most of the researchers found that income inequality is negative relation with the development of a country whereas it is good for the economic growth.

Although the results suggested that some researchers postulate that income inequality cannot separate with education inequality. Therefore, there is a limit of economic growth during for checking Gini index from 2007-2015. It is a view of deficiency in the measurement of education, no enrollment ratios, the average schooling years, educational Gini in four provinces of Pakistan. The data is used from 1973 to 1998. The technique is used such as Education Kuznets curve, Lorenz curve, Gini index, Macro-Mincerian function. The results show that there is negative relationship between educational inequality opportunities and average schooling years. Whereas, it is found that Public sector is extremely strong impact of education inequality on economic growth along with do not utilize the expenditure of education properly. According to the researcher that it is recommended the policy to focus on primary education rather than higher education. Farooq (2017) goes through the effect of schooling and education on income inequality in Pakistan. To compute income inequality through the Gini coefficient technique by using data from (PSLM) survey of 2004-2005 of (FBS), Islamabad. The results indicate that it is found to be unequal in distribution of income between male and female labor force. There is a higher inequality in male than female. The value of Gini coefficient of urban is (0.341) as compare to rural (0.261) whereas value of Gini-coefficient is 0.301 . The results shows that schooling and education are extremely affected the distribution of income in context of the people. Thus, the study indicates that there should not discriminate between employment and equal opportunity of schooling as well.

Zhang, Li, and Xue (2015) examines the rural along with urban in context of pedagogy inequality. Researchers and policymakers are the key interest in a potential line for human development accumulation. The data is used to check literacy rendering in rural in addition to children and the migration children during 2009-2010. Thereby indicate children education is importantly low as compare to urban equivalence even after checking the distinction between nutrition and parenting level. Therefore, it is necessary to reduce the differences between Rural and Urban education inequalities to facilitate human assets build-up (PRC). Saeed and Fatima (2011) estimate education inequality in different districts of Sindh. It is calculated the education through Gini index individually 
in agriculture and metropolitan areas and went through alter of education inequality from 2004-05 to 2010-11. It is indicated that there is a highly inequality in education. Although, it is decreased 2004-05 and 2010-11. However, 50\% is remained in Gini index in 2010-11. There is clearly disparity is worth seen in education inequality in rural urban areas of districts of Sindh. It occurs negatively relationship between education Gini index and the average year of schooling.

Jamal and Jahan (2005) concluded that developed countries are made progress by leaps and bounds owing to huge investing in education. Therefore, education is a multidimensional progress and immensely important for the economic growth of a country. Education does not only decrease income inequality but also reduce poverty at all. The objective of study is to investigate many vital factors of poverty, physical capital and education on economic growth in Pakistan. The study is indicated phenomenological approach which investigates the various aspect of income and education inequality in developing countries like Pakistan. The methodology also suggests that how can we decrease the income inequality in Pakistan. This study is based on primary research during interviews, professional people, Economists, highly educated people and various types of themes are evaluated. Their themes are income level, government's role, feudalism, education system, geographical inequality, etc but the main object is to decrease the income inequality. If the education will be up to the mark then the level of income inequality will be decreased and vice versa. It is found that impact of per capita income has negative due to unequal distribution of education. For instant, Casetello and Domenech (2002) reveal that difference in pedagogy is thoroughly connected to low income growth rates \& low investment rates. It investigates the policies for advancing progress must do it seriously. Hassan et.al (2019) consider the negative impact of education inequality on economic growth. The study indicates that educational inequality is a major human capital inequalities and growth in an economy in different provinces of Turkey. Recently Ibourk, A. and J. Amaghouss (2013) also explore that it is negative impact on economic growth. The main object of the study is to examine education difference in the division of education is different provinces of Pakistan in rural and urban areas.

In Pakistan, very few number of researches are found the computation education imbalance such as Saeeda (2009) as well as Noman (2011) is proverbial. Whereas; the study point of view is separate. It calculated education inequality amid together population for agriculture and urban sections of four territories including the Islamabad. The main emphasis of the learning is to population whose age is 15 years and above who do not get education in any institutes and similar practices for the employment of citizens.

Quarles et al. (2020) has indicated that myriad students drop out each year in USA and billions of dollars has been used in reforming educational system. It can be examined easily measurable student features through existing research. Nevertheless, various measurable go through the characteristics of the students, skills, and funds effects educational success. It shows a conceptual framework for the combine of all factors especially students capital. We advance by using methods of student's capital. Student's capital is giving out exponentially in each of 140 groups of students of college. Students' ability is always to be successful but there is a limit resource, given out inequality etc. The results investigate that it should be built up the skills, and expansion of resources to be successful in school and colleges rather than limit barriers in context of easily measured characteristics. Maliti (2019) investigated regarding inequality in Tanzania which is dependent on different houseful survey. The literature is based on beyond its limits. As results of that inequality is ignoring for longer period. This study is used for six rounds of methodological health survey and demographic to show six month traditional health as well as educational inequality at Tanzania.

It continues and is decreasing between rural as well as urban areas especially Dar se Salam and alternative region as well. Although, Gender inequity is also reducing in education constantly across different age ranges wherever, affluent inequality is calculated by a blended index is reducing. Mostly, the result is decreasing part of households is the poorest, by making use DHS's alternative index to 
choose assets. The Tanzania culture is growing exponentially occurring equally between wealth as well as education it is discussed scheme option for reducing inequalities. Pathania et.al (2020) is trying to go through the education inequality, progress of literacy and literacy inequality male and females of literacy inequality is inspected from 1951 to 2011 by using Census wise data. The present study, literacy inequality is focused at national level. Literacy rate is differentiated between various states of India and inequality areas wise (rural and urban). Education inequality is also calculated at different level of education from 2005 to 2014. Thereby, it is indicated that literacy inequality has been decreased at province level. Country level and also rural and urban areas but unfortunately females' literacy inequality is high in rural as contrast to urban areas. It is also examined which education inequality is higher at higher education level as contrast to primary, elementary, secondary and higher secondary levels.

Arshed et al. (2020) found that when firms do not get which labor is efficiently worked there option seems to be feasible to pay all either good workers or bad workers. They are ready to give them. In fact, good workers are discouraged when you give equal wage to bad workers. Spencer suggested using educational attainment to show their capability to solve the problems. Although, workers are randomly divided in context of their ability. Akerlof proposed that the educational attainment should be focused individually which is not recognized practically. In the present study, it strives to research the impact of education inequality. However income inequality of the household is the initial suspect along with gender, age, and household size. GMM approach is used to find the effect of income inequality on education inequality. The results indicated that it is highly barriers of income inequality which holds people from getting higher education. Shahabadi et al. (2018) indicated that the impact of education is highly challenging issue on income inequality is the main economic debates. This study is tried to find out the effect of income inequality in a selected of Islamic countries from 1990 to 2013 and the method has been used as panel data and the Hausman test as well. It is investigated through the impact of training and Gross Domestic Product (GDP) at primary, elementary, secondary, higher secondary, and higher education level on income inequality in selected Islamic countries. The results found that the there has a significant negative effect of primary and secondary schools on earning inequality while the being enrolled of institutes has a favorable impact of earning inequality. Thereby, the instruction might reduce income inequality at primary and secondary schools whereas higher education can increase inequality due to financial burden of certain classes of people. Similarly, the Kuznets inverted-U statement which is sanctioned owing to the positive and significant estimation of coefficient of income statistically and negative along with significant of its square value. Thereby, it is indicated that in the first aspect of economic growth and the distribution of income is increased unequal. This inequality can be reduced if the distribution of income can be treated equally.

Chaudhry et al. (2009) indicated effect of male-females educational inequality on rustic poverty by working logit hypothesis analysis on initial data places in Pakistan. In a nut shell, there is opposite relationship between gender disproportion in education as well as pastoral poverty. The pronouncement recommended which man-feminine literacy ratio, male-female being enrolled ratio, female as well as male ratio of entire years of education; female as well as male ratio alarming as well as learning of household head have dissenting significant effect on rural scarcity. Thereby, suggest that female in addition to male ratio and a household size has vigorous favourable alliance. Gumeniuk (2017) states that Russia's development was reinvigorated between the social development of the Russian federation and other Baltic region states in terms of living standards. The proverbial countries comparison is mixture that incorporates many composite affecting the quality of life. This study analyses the present level and also in the social development of the Baltic states from 1990 to 2016. This analysis is purely based on the values of human development Index which is included advantages and disadvantages country's social development. A statistical analysis executed with the help of HDI 
values which is divided the Baltic States into three groups Baltic States are making progress by leaps and bounds in terms of development level and advancement trajectories.

The progress of Baltic States was highly observed in 2006. Later on, it was reduced gradually in the social development of the third group like Latvia, Russia and Lithuania- accelerated. The progress of Baltic States' suggests about social development from 2015 to 2016 that social development will decrease in coming years across the region and the gap will arise among the countries. Unterhalter et al. (2006) analyses the measuring gender inequality in education in south Asia whereas progression data are very important step towards gender especially girls in school which are provided inequality in schools. There is a dire need to identify the gap of male and female especially in rural areas where females ratio are highly unequal in terms of male. Thus inequality can be found out where data is available of inequality of rural and urban areas of education. Though, quality of education measures a significant role in gender equality. In view of economic and gender indicators together with education do not consist patterns of emerging in gender inequality in education. This study shows the Gender Equality in Education Index (GEEI) which is measured to develop a data sources to envision gender equality in education in more measurement than simply enrolments. The data indicates that there were improvements in 1990s in context of GEEI of the South Asian countries except Pakistan.

The GEEI reached the higher gender and education MDGs which is required huge mobilization in the previous decade and increasing in many countries as well. The GEEI assesses some indication of the size of the task and a dire need to mobilize them. Kang H. Park (2017) analyses that how income, globalization, and education impact inequality in Asia, along with required balanced and panel data. The evidence considers that Kuznets- $U$ statement is connected between income inequality and education level. Whereas, more variable are incorporated into the model, As a matter of fact, they continue of the opposite U-shape curve occurs weaker. The facts and figures indicate that education variables are highly affected by income distribution. Our suggestion gives that a higher level of education succeeded by the population aged 15 and above and drastically has increased income distribution in Asia. Whereas education Gini Index calculated educational inequality which has a negative impact on income inequality, while economic, political and freedom have additionally been influenced on the level of inequality of income distribution. Kenechukwu (2020) goes through that the effect of gender inequality in education analysis through Sub-Saharan African Countries on economic growth. Two gender inequalities are indicated and find the gap in secondary enrolment and female as well as male primary.

This study is to build Solow Model and also used between human assets and health care outlay (HEC) per capita.Factual dissection is used on yearly data of forty half-Sahara African Countries from 1990 to 2018. The evaluation of employed is used in a panel data set within group and both Fixed effect and Ordinary Least Square (OLS). In a nut shell, the centre findings suggested which presents a meaningful negative association of gender inconsistency and secondary level and effect on economic growth while there is also lack of female labor contribution on economic expansion. Noman et.al. (2019) examines the correlation between income along with education imbalance among Asian growing Countries and data is used from 1960 to 2015. OLS and group co integration are used for the estimation of long-run coefficient. Thereby, it is initially primary, secondary, and tertiary enrolment arises inequality whereas many researchers find and same as this paper also find out that impact of learning on earning imbalance has refused during minimum as $97.5 \%$ for initial, $43.5 \%$ secondary and 11\% tertiary as well. Therefore, the results consider Kuznets of an upturn-U curve association among primary, lower level, and tertiary enrolments. 


\section{DATA AND METHODOLOGY}

The data is used lying on the recent version of micro data of (PSLM) from 2014 to 2015. PSLM is basically presented by Pakistan Bureau of Statistics. It incorporates comprehensive information regarding 78,635 households consisting 513,945 separates of which 295,310 are of time 15 years and higher than. The study calculates the didactic achievement level by completing years of education separately. Therefore, the study have taken 0 to 18 of learning as calculate of enlightening accomplishment. In our research, 0 stand for illiterate, 1 stand for 1 year education, 2 stand for 2 years of education and so on. As far as farming, processor, and engineering degree are concerned. We have taken 16 years of schooling while we have taken medicine degree as 17 years of education moreover, we have taken M.Phil as 18 years of learning. Therefore, we have merely those selected and completing their learning and are not being enrolled. The aim is to differentiate schooling of those who are currently enrolled may give play down condition in context of educational inequalities.

As a matter of fact, there are many different researchers such as Wang (1999), Abdelbaki (2012) and Ibourk and Amaghouses (2013) and many others find that there is no specific method to measure educational inequalities. Although, there is generally method to calculate education inequality that is Gini Coefficient of educational inequality which is ascribed by Gini (1912). The Gini Index is also called Gini Coefficient. It is used for measuring the sharing of income over the people urbanized by the Italian Statistician Corrado Gini (1912). It is generally second-hand for measuring of financial inequality, distribution of revenue, or less affluence allocation among residents. The Gini Coefficient covers from 0 (or $0 \%$ ) to 1 (or 100\%), 0 means perfect equality while 1 constitutes perfect inequality. The range of 1 hypothetically feasible owing to unhelpful profits or assets. For example a country where every citizen has the same income and the Gini Coefficient of income is 0. They have earned all the income. It means that there is perfect equality among people in a country whereas other citizen does not earn anything, will gauge revenue Gini Index of 1 . The same analysis can be applied to education inequality where we will identify rural and urban areas of Pakistan and will measure through Gini Coefficient. The Gini Coefficient is a pivotal role for considering income or wealth distribution within region or country. It is explained geometrically as the part of the region amid the line of total parity plus the Lorenz shape toward absolute vicinity beneath the line of total equality. Change of Gini Index, as a gauge of enlightening inequalities is composed like

$$
G_{\mathrm{E}}=1-\sum_{i=1}^{n} p_{\mathrm{i}}\left(c y_{i}+c y_{i-1}\right)
$$

Although, $G_{\mathrm{E}}$ is the abbreviation of instructive Gini Index which is defined on the didactic achievement of entity, whereas $p_{\mathrm{i}}$ is defined as the populace split, and $c y_{i}$ is the collective learning share of the personage $i$, whereas, everyone is remaining in rising order for existence of schooling. There are some reward of employing Gini Index, likewise there is invariable in the direction of corresponding alter in the instruction levels of the entire people; there is autonomous individual recognized of an individual and has explainable ranges.

\section{RESULTS AND DISCUSSION}

In this section, the consequences interpret and investigation accordingly. As the study have already discussed that we are focusing individually who have done their education completely and are not presently enrolled elsewhere. In Table 2, we give the evaluation of Gini Coefficient for education attainment. Pakistan Bureau of Statistics reported in Table 2 clearly defined there is significant educational inequalities in provinces of Pakistan except Islamabad. Furthermore, the statistics express 
that inequality in instructive accomplishment fall greatly for earners. For example, the Gini Index indicates population ranges from 0.418 to 0.929 inequalities in educational attainment and as for as earners are concerned it sets as of 0.315 to 0.853 . Though, this decrease is extremely clear that earners are generally better education like contrast to those who are not earning. In this way, difference decrease between earners in education. This data clearly show that earners are normal years of education around 5; meanwhile, non-earners are average years of schooling approximately 2.24. Furthermore, illiterate of people is $72 \%$ meanwhile, $47 \%$ are earners only. As a matter of fact, these statistics are clearly indicated that there is immensely low level of educational differentiate among earners.

Table 2. Educational Inequalities in Rural and Urban Areas of Pakistan

\begin{tabular}{lccccccc}
\hline Provinces & \multicolumn{3}{c}{ Population age 15 years \& above } & \multicolumn{3}{c}{ Earners age 15 years \& above } \\
\hline \multirow{3}{*}{ Khyber } & & Overall & Male & Female & Overall & Male & Female \\
Pakhtoonkwa & Rural & 0.768 & 0.65 & 0.871 & 0.583 & 0.559 & 0.815 \\
& Urban & 0.644 & 0.539 & 0.744 & 0.431 & 0.418 & 0.535 \\
Punjab & Rural & 0.682 & 0.591 & 0.767 & 0.609 & 0.552 & 0.832 \\
& Urban & 0.531 & 0.479 & 0.582 & 0.424 & 0.402 & 0.533 \\
Sindh & Rural & 0.78 & 0.675 & 0.889 & 0.66 & 0.642 & 0.853 \\
& Urban & 0.597 & 0.52 & 0.677 & 0.46 & 0.443 & 0.615 \\
Baluchistan & Rural & 0.802 & 0.685 & 0.929 & 0.663 & 0.648 & 0.835 \\
& Urban & 0.699 & 0.569 & 0.84 & 0.489 & 0.477 & 0.588 \\
Islamabad & Rural & 0.49 & 0.418 & 0.556 & 0.359 & 0.315 & 0.528 \\
\hline
\end{tabular}

Source: Author's estimation

As above facts and figures mentioned that learning inequalities are extremely squat in Islamabad. The reasons are so as to Islamabad is well organized, planned, high standard of living, safety and abundant greenery. Here, equal and average opportunities of education are present. In fact, all areas of Islamabad have almost schools and colleges. Similarly, transport facilities and basic infrastructure are present for all citizens of Islamabad. Therefore, education is quite attainable along with people of Islamabad are extremely more aware of learning of their kids. It is too to be pointed out to there are numerous government houses, offices, personal organizations, semi-government, ministries, banks, NGO's, universities, and overseas embassies as well. These shows to advance require for education and are contributed. When we compare Rural as well as urban education inequality. We will find that there is highly education inequality in rural areas. This indicates that there are no appropriate education facilities in rural area where children can learn effectively in the native home. Although, primary, elementary and secondary schools are present but unfortunately, colleges are not available in rural areas where students can get higher education in their premises.

Furthermore, there are almost not available universities in pastoral areas of Pakistan. As result, a huge number of students do not get their further education after matric. Eventually, they ended their education. Besides, the rural households are extremely busy in cultivation, live-stock to its connected field. The reason is that there are no other opportunities to avail them. In fact, in this two field, such type of education does not require. Therefore, they quit education and continue their dynasty field of agriculture and live-stock. However, some people insist for higher education and those who have financially strong and ready to pay fees of the university and other expenses of the other cities as well but there are small numbers of people who are ready to pay fees for higher education and other 
expenses as well. Therefore, a large education discrepancy exists in rustic areas. The differentiate among provinces explain to the education discrepancy is utmost in Baluchistan and then Sindh.

It is one of promising reason is that these two provinces are diverse from KPK and Punjab. For instance, the rural areas of Sindh and Baluchistan are typically dominant system of unofficial politics as well as highly influenced by Sardar/Wadras system that have least interest to promote the education system at its top priority. Therefore, they avoid improving educational system. As a matter of fact, Sindh and Baluchistan decrease their allocated funds during FY2016 for new development projects of education whereas KPK and Punjab increased the funds. According to the Economic Survey of Pakistan (2017-18), KPK, and Punjab arises the funds by $15.2 \%$ and $32.3 \%$ individually meanwhile, Sindh as well as Baluchistan contract the money by $1.5 \%$ and 11.5 separately. Furthermore, the figures of learning institutions of Baluchistan are $20 \%$ less than the education institutions in Punjab. Before entering into a new phase of education, a large apt of population do not get their education owing to the non-availability of education institutions. Only rich class can get their higher education to pay their fees and other expenses of the other cities. As a result, educational discrepancy increases in four provinces.

Table 2 indicates learning inequalities athwart gender as well. The same tendency is provided in each four provinces including Islamabad. It is one of the feasible reasons of physically powerful family system in Pakistan. It is our traditional family system that it is the sole economic responsibility of the male house and does not give permission to earn mostly. Thereby, the main object of male is to get education for the purpose to get a job and earn along with the cultural values, norms, attitude and custom do not allow female to move from one place to another place for education and even job or any other objects. If she is willing in case of mobility she will get company of male members of family. In this way, drop ratio of females in education is within a family due to such type of values in rural areas. Thus, female can only get education those who have financially strong and belong to educated family in rural areas as well. Thereby, a large number of females do not continue their education due to lack of facilities in education to get higher education in rural areas or home town.

Table 3. Literacy Rate in Percent (10 years and above) - Pakistan and Provinces.

\begin{tabular}{|c|c|c|c|c|c|c|}
\hline \multirow[t]{2}{*}{ Province/Area } & \multicolumn{3}{|c|}{$2015-16$} & \multicolumn{3}{|c|}{ 2018-19 } \\
\hline & Male & Female & Total & Male & Female & Total \\
\hline Pakistan & 70 & 48 & 58 & 71 & 49 & 60 \\
\hline Rural & 63 & 36 & 49 & 65 & 38 & 51 \\
\hline Urban & 81 & 68 & 74 & 80 & 67 & 74 \\
\hline Punjab & 72 & 54 & 62 & 73 & 57 & 64 \\
\hline Rural & 66 & 44 & 55 & 67 & 47 & 57 \\
\hline Urban & 82 & 73 & 77 & 82 & 73 & 77 \\
\hline Sindh & 67 & 44 & 55 & 68 & 44 & 57 \\
\hline Rural & 51 & 19 & 36 & 55 & 21 & 39 \\
\hline Urban & 80 & 65 & 73 & 79 & 64 & 72 \\
\hline $\begin{array}{l}\text { Khyber Pakhtunkhwa } \\
\text { (Including Merged Areas) }\end{array}$ & - & - & - & 75 & 36 & 55 \\
\hline Rural & - & - & - & 74 & 33 & 52 \\
\hline Urban & - & - & - & 82 & 51 & 66 \\
\hline $\begin{array}{l}\text { Khyber Pakhtunkhwa } \\
\text { (Excluding Merged Areas) }\end{array}$ & 72 & 36 & 53 & 76 & 40 & 57 \\
\hline Rural & 70 & 33 & 50 & 81 & 54 & 67 \\
\hline
\end{tabular}

Source: Economic Survey of Pakistan (2018-19)

Literacy rate has been taken since 10 years and above Pakistan and Province wise as well. According to Economic Survey of Pakistan (2015-16), Literacy rate shows that male and female are $70 \%$ and $48 \%$ in Pakistan and overall literacy rate was 58\% whereas Punjab is utmost in total literacy rate was $62 \%$ followed by Sindh $55 \%$ and KPK $53 \%$ as well. Nevertheless, according to the Economic 
Survey of Pakistan (2018-19), total literacy rate was 60\% whereas rural of male $65 \%$ and rural of female $38 \%$ while urban literacy rate of male was $80 \%$ followed by female literacy rate was $67 \%$. In fact, literacy rate of Punjab improved as compare to Economic Survey of Pakistan (2015-16). Total literacy rate of Punjab was $64 \%$ which is higher than other provinces of Pakistan. Nevertheless, rural literacy rate of female of Punjab was $47 \%$ and male $67 \%$ along with urban literacy rate of male and female was $82 \%$ and $73 \%$ as well. Whereas Sindh total literacy rate was $57 \%$ total rural literacy rate was $39 \%$ and urban $72 \%$. We can clearly see that rural literacy rate is relatively low as compare to urban literacy. At the end KPK total literacy rate was 55\% whereas urban literacy rate was $66 \%$ while rural literacy rate was $52 \%$. It shows that rural literacy rate is relatively low as compare to urban areas. This study clearly indicates that overall four provinces of rural areas are extremely low in literacy rate. Therefore, there is a dire need to provide basic facilities such as primary, secondary, higher secondary, and universities to rural areas of Pakistan.

\section{CONCLUSION}

Education is an important component of human capital that causes to development and growth for any country. Education permits citizens by arising their opportunities to participate in manual labor market. Advanced education always gives high results in terms of opportunities and innovation while lower education provides disparity in opportunities and innovation as well. Thus, difference in education leads to poverty and income inequality. This study tries to measure education inequality all over Pakistan. We also evaluate the learning inequality in rural in addition to urban areas of four provinces including Islamabad. Data is used from PSLM (2014-15) for analysis the 15 existence of age and over who is not being enrolled in any learning institutions. PSLM (2014-15) incorporates in order which is related to education of 2, 95,310 individuals and having 15 existence of age and over. There are $38.8 \%$ of population are employed, meanwhile the entire of population are without a job. The facts and figures explain significant educational disparities overall population. In this same, it is worth mentioning that educational disparity exists in rural as well as urban areas of all four provinces of Pakistan.

The results clearly indicate the values of Gini Coefficient are higher than 0.417 which gives a significant educational gap of all over population of Pakistan. It is notable that the employed population shows Gini Coefficient and expresses educational inequality. However, the stage of strength of education inequality is employed population is extremely low. According to Economic Survey of Pakistan (2019-20) there is only 60\% of literacy rate in Pakistan which is the lowest among the South Asian countries. It is notable that literacy definition means that who can read and write its name is called literate person. Therefore, the condition of education is deplorable in Pakistan. Although, the average of the level of educational inequality endures elevated in rural areas as compare to metropolitan areas. In this way, lack of education is high among females as contrast to male population whereas Baluchistan and Sindh are high in lack of education and then followed by KPK and Punjab as well. In fact, the condition of education of Islamabad is extremely satisfactory as compare to all provinces of Pakistan where education disparity is extremely low.

Thus, the current education disparity urges that the strategy makers must give ultimate magnitude to schooling in all provinces of Pakistan which provides equal education for both male and female especially in rural areas of Pakistan. It is worth notable that it is highly necessary steps to improve education system in both Sindh and Baluchistan especially in rural areas of both provinces. In this paper, the main focus is to measure the educational inequality in Pakistan. Future work can be done by remove the subsequent ranges. We calculated lack of education which is purely established on the completing years of education, but unfortunately, we do not provide excellence of learning at 
all. Similarly, we determine enlightening difference established on the basis of the official learning whereas it does not give properly years of education for unofficial education along with we do not ascertain sectoral differences. Consequently, upcoming researchers can go through educational inequalities over many sectors of Pakistan.

\section{REFERENCES}

Abdelbaki, H. H. (2012). An analysis of income inequality and education inequality in Bahrain. Modern Economy, 3(5), 675-685.

Agupusi, P. (2019). The effect of parents' education appreciation on intergenerational inequality. International Journal of Educational Development, 66 (5), 214-222.

Arshed, N., Anwar, A., Hassan, M. S., \& Bukhari, S. (2019). Education stock and its implication for income inequality: The case of Asian economies. Review of Development Economics, 23(2), 10501066.

Arshed, N., Hassan, M. S., \& Aziz, O. (2020). Does Income Inequality Lead to Education Inequality?. UMT Education Review, 3(1), 45-68.

Br, C., \& Issue, E. S. (2011). the Impact of Income Inequality and Educational Inequality on Economic Growth - a Literarure Review. Analele Universității Constantin Brâncuşi Din Târgu Jiu : Seria Economie, 1(4), 59-65.

Castelló, A., \& Doménech, R. (2002). Human capital inequality and economic growth: some new evidence. The economic journal, 112(478), C187-C200.

Chaudhry, I. S., \& Rahman, S. (2009). The impact of gender inequality in education on rural poverty in Pakistan: an empirical analysis. European Journal of Economics, Finance and Administrative Sciences, 15(1), 174-188.

Fares, J., \& Garcia, M. (2010). The Effect of Education on Income and Employment. Youth in Africa's Labor Market, 14(2), 39-48.

Farooq, M. (n.d.). Farooq, M.pdf. Gumenyuk, I. S. (2017). Human Development Index as a Tool to Assess Social Development in the Baltic States. Baltic Region, 9(3), 45-57.

Investigation, A. N., Motivation, O. F. E., \& Iraqi, O. F. (2020). International Journal of Education Humanities and Social Science. 3(2), 25-36.

Ibourk, A. and J. Amaghouss (2013) "Inequality in Education and Economic Growth: Empirical Investigation and Foundation - Evidence from MENA Region", International Journal of Economics and Finance, Volume:5, Number: 2, 111-124.

Jamal, H., \& Jahan Khan, A. (2005). The Knowledge Divide: Education Inequality in Pakistan. The Lahore Journal of Economics, 10(1), 83-104.

Lam, D. (2020). The Political Economy of Inequality: U.S. and Global Dimensions. In The Political Economy of Inequality: U.S. and Global Dimensions. https://doi.org/10.17848/9780880996730

Lynd, D. (2007). The Education System in Pakistan: Assessment of the National 
EducationCensus.Unesco,142.Retrievedfromhttp://unesco.org.pk/education/teachereducation /files/sa4.pdf Maliti, E. (2019). Inequality in education and wealth in Tanzania: A 25-year perspective. Social Indicators Research, 145(3), 901-921.

Maliti, E. (2019). Inequality in education and wealth in Tanzania: A 25-year perspective. Social Indicators Research, 145(3), 901-921.

Osathanunkul, R., \& Keawngamdee, C. (2003). Gender Inequality in Education and Economic Growth in ASEAN Member Countries. Human Resource Development Review, 3(4), 40-46.

Park, K. H. (2017). Education, Globalization, and Income Inequality in Asia - Asian Development Bank Institute. ADBI Working Paper Series, 1(732), 1-20. Retreived from https://www.adb.org/sites/default/files/publication/301271/adbi-wp732.pdf

Pathania, R. (2020). Literacy in India : Progress and Inequality. Bangladesh E-Journal of Sociology, 17(1), $57-65$.

Quarles, C. L., Budak, C., \& Resnick, P. (2020). The shape of educational inequality. Science Advances, 6(29), eaaz5954.

Saeed, N., \& Fatima, A. (2015). Educational inequality in rural and urban sindh. Pakistan Development Review, 54(4), 767-777.

Schultz, T. W. (1961). Investment in human capital. The American economic review, 51(1), 1-17.

Turčínková, J., \& Stávková, J. (2012). Does the Attained Level of Education Affect the Income Situation of Households?. Procedia-Social and Behavioral Sciences, 55, 1036-1042.

Tschurenev, J. (2018). Inequality, Difference, and the Politics of Education for All. Südasien-Chronik - South Asia Chronicle, 1-19.

Unterhalter, E. (2006). Measuring gender inequality in education in South Asia. Retreived from http://www.worldcat.org/oclc/373090621

Witzke, H. (1984). A model of income distribution in agriculture: Theory and evidence. European Review of Agricultural Economics, 11(1), 65-83

Yang, J., Huang, X., \& Liu, X. (2014). An analysis of education inequality in China. International Journal of Educational Development, 37(9), 2-10.

Zhang, D., Li, X., \& Xue, J. (2015). Education inequality between rural and urban areas of the People's Republic of China, migrants' children education, and some implications. Asian Development Review, 32(1), 196-224. 